(2) Open Access Full Text Article

\title{
Synergistic Cytotoxic Effect from Combination of Wedelolactone and Cisplatin in HeLa Cell Line: A Novel Finding
}

This article was published in the following Dove Press journal: Drug Design, Development and Therapy

\author{
Sadia Sarwar $\mathbb{D D}^{1,2}$ \\ Jun Qing Yu' \\ Humaira Nadeem ${ }^{3}$ \\ Fazlul Huq' \\ 'Discipline of Biomedical Sciences, \\ Sydney Medical School, The University of \\ Sydney, Cumberland Campus, Sydney, \\ NSW, Australia; ${ }^{2}$ Department of \\ Pharmacognosy, Riphah Institute of \\ Pharmaceutical Sciences, Faculty of \\ Pharmaceutical Sciences, Riphah \\ International University, Islamabad, \\ Pakistan; ${ }^{3}$ Department of Pharmaceutical \\ Chemistry, Riphah Institute of \\ Pharmaceutical Sciences, Faculty of \\ Pharmaceutical Sciences, Riphah \\ International University, Islamabad, \\ Pakistan
}

Context and Objective: Cisplatin is a platinum drug in current clinical use for the treatment of cervical cancer. However, drug toxicity and resistance are its two major limitations. The aim of this investigation was to test the cytotoxic activity of potential phytochemicals alone and in combination with cisplatin in cervical cancer cells.

Methods: In this study, cytotoxicity of phytochemicals including wedelolactone (WDL), betulinic acid (BA) and epigallocatechin gallate (EGCG) was investigated in human cervical cancer cell line HeLa through 3-(4, 5-Dimethyl-2-thiazolyl)-2, 5-diphenyl-2H-tetrazolium bromide (MTT) reduction assay. Combined drug action resulting from the combination of cisplatin with WDL and BA was investigated in the same cell line through median effect principle. The combination index (CI) was taken as a measure of combined drug action.

Results: BA resulted in synergistic outcome when co-administered with cisplatin at $0 / 0$ time; (bolus administration) while administration of either drug (cisplatin or BA) four hours before the other $(0 / 4$ or $4 / 0)$ resulted in antagonistic action. WDL, on the other hand, was found out to be synergistic at any of the applied sequence of drug administration $(0 / 0,0 / 4$ or 4/0).

Discussion and Conclusion: This is the first study reporting cytotoxic activity of WDL in HeLa cells either as single agent or in combination with cisplatin. These results support the idea that sequential combination of cisplatin with WDL and BA may work effectively in cervical cancer cells.

Keywords: HeLa, wedelolactone; WDL, betulinic acid; BA, MTT reduction assay, combination index; CI, synergism

\section{Introduction}

According to NIH statistics, 13,800 new cases of cervical cancer and 4,290 resulting deaths are expected in 2020. These figures show that cervical cancer is most likely to remain one of the leading causes of death among women. In the US, it makes up to $0.8 \%$ of all new cancer cases. ${ }^{1}$ Cisplatin (cis-diamminedichloroplatinum II, CDDP), an inorganic platinum compound, is one of the effective chemotherapeutic agents in the treatment of cervical carcinoma. It is in clinical use as a first line monotherapy and also in combination with other chemotherapeutics against local, advanced and recurrent/metastatic cervical cancer. ${ }^{2-9}$ The overall response rate is $29.1-67 \%$ while median overall survival is almost 12 months in recurrent/advance cervical cancer patients receiving combination chemotherapy. However, development of chemoresistance to cisplatin, intrinsic or acquired, seriously compromises the treatment.
Correspondence: Sadia Sarwar Department of Pharmacognosy, Riphah Institute of Pharmaceutical Sciences,

Faculty of Pharmaceutical Sciences, Riphah International University, Islamabad, Pakistan

Tel +92-333-5565889

Email sadia.sarwar@riphah.edu.pk 
Cisplatin is a small molecule originally identified as antibacterial agent. Mechanisms underlying the cisplatin mediated anticancer effects are associated with several signaling pathways. The most remarkable effects of cisplatin are changes in DNA conformation and damage induced by DNA-cisplatin adducts. However, DNA damage is nonselective leading to toxicities and adverse side-effects such as nephrotoxicity, gastrointestinal toxicity, neurotoxicity, bone marrow toxicity and ototoxicity. ${ }^{10}$ Therefore, it is necessary to continue searching for new anticancer compounds and/or adjuncts to current treatments. Many compounds have been found to inhibit early stages of carcinogenesis in experimental models. Among them are recognized drugs (e.g., nonsteroidal anti-inflammatory drugs abbreviated as NSAIDs) and phytochemicals. When used in combination with cisplatin or other $2 \mathrm{nd}$ and $3 \mathrm{rd}$ generation platinum drugs, phytochemicals can offer promising benefits in terms of compromising the toxicities or inducing the sensitization towards chemotherapeutics or reducing the drug dose. The number of studies reporting such combinations in basic research is on continuous rise where phytochemicals-induced sensitization of cancer cells to chemotherapeutics has been observed. ${ }^{11-13}$

$N F-k B$ family members regulate hundreds of genes involved in immune-regulation, inflammation, apoptosis and carcinogenesis. ${ }^{14}$ It has been established that constitutive activation of $N F-k B$ inhibits chemotherapy induced apoptosis in cervical cancer, as well as in other types. In literature, combination of cisplatin with $N F-k B$ inhibitors has been suggested to have therapeutic significance. ${ }^{15} \mathrm{Bcl}$ 2 family constitutes multiple anti-apoptotic proteins associated to the poor clinical response being over-expressed in cisplatin resistant cervical cancer cells. ${ }^{16}$

Caspases $(3,8,9)$ play a pro-apoptotic role and their reduced levels have been found to be associated with cisplatin resistance in cervical cancer cells. Up-regulation of pro-apoptotic effector proteins may contribute to overcome the resistance to cisplatin because in many resistant cases, up-regulation of anti-apoptotic and suppression of proapoptotic proteins has been observed. ${ }^{17}$ Mitogens activated protein kinases (MAPKs) are another class of proteins regulating gene expression in response to extracellular stimuli (stress activated $S A P K / J N K$ and extracellular signal regulated kinases (ERKS). Inhibition/down-regulation of MAPKS contributes to resistance to cisplatin in cervical cancer while their activation can be a promising strategy to enhance cisplatin-induced apoptosis. ${ }^{18-20}$
Epigallocatechin gallate (EGCG), betulinic acid (BA) and wedelolactone (WDL) are reported inhibitors of $N F$ $\mathrm{kB}, \mathrm{BCl}-2$ and activators of caspases and MAPKs. ${ }^{21-23} \mathrm{In}$ this study, we investigated the effects of these phytochemicals on the survival of resistant cervical cancer cell line HeLa singly as well as in combination with cisplatin in vitro in the hope of finding synergistic combinations to overcome resistance and/or as adjuncts.

\section{Materials and Methods \\ Reagents}

Cisplatin was prepared according to the method of Dhara. ${ }^{24}$ WDL, EGCG and BA were purchased from Sigma Aldrich, Sydney, Australia. Dimethylformamide (DMF) was purchased from Sigma Chemical Co. (St. Louis, MO USA). All other chemicals and solvents used in the study were of analytical grade. HeLa cell line was a gift from Dr Mu Yao, Department of Endocrinology, University of Sydney, Australia and were purchased from ECACC (93021013).

\section{Cell Lines and Preparation of Stock Solutions}

The experiment was performed at Discipline of Biomedical Science, School of Medical Sciences, University of Sydney, Australia. The cell line was sub-cultured in RPMI 1640 medium that was prepared in $10 \%$ fetal calf serum (FCS, $1 \mathrm{mM}$ Hepes, $5.6 \%$ sodium bicarbonate and $200 \mathrm{mM}$ glutamine). $1 \mathrm{mM}$ solution of cisplatin was prepared by initially dissolving it in dimethylformamide (DMF) followed by addition of milli Q (mQ) water (ration 1:5). WDL, BA and EGCG were dissolved directly in DMSO to get $1 \mathrm{mM}$, $10 \mathrm{mM}$ and $1 \mathrm{mM}$ solutions respectively. The solutions were sterilized by filtering using DISMIC-25cs ADVANTEC filter (cellulose acetate, $0.20 \mu \mathrm{m}$ hydrophilic, pressure limitation: $0.51 \mathrm{MPa}$ ). The stock solutions were serially diluted with freshly prepared RPMI-1640 medium to produce a range of final concentrations used.

\section{Cytotoxicity Assay for Single Drugs}

The cell survival fraction was determined using the 3-(4, 5-Dimethyl-2-thiazolyl)-2, 5-diphenyl-2H-tetrazolium bromide (MTT) reduction assay. This assay is based on the principle that yellow coloured MTT dye is reduced in living cells to a purple formazan crystals which is measured as absorbance values through spectrophotometer ${ }^{25}$ Cells were seeded, at concentration of 4,000 to 5,000 per well in RPMI-1640 medium, into flat-bottomed 96-well 
culture plate and allowed to attach overnight. For single treatments, drugs were added at a range of four concentrations (shown in Figures 1-3) to triplicate wells and left in incubator $\left(37 \mathrm{C}^{\circ}, 5 \% \mathrm{CO} 2\right.$ in air, $\left.\mathrm{pH} 7.4\right)$ for 72 h. After preparation of serial dilutions of the drugs in $10 \%$ FCS/RPMI 1640 medium, $100 \mu \mathrm{L}$ of medium was added to cell cultures in triplicate wells. The cells were then left to incubate under normal growth conditions for $72 \mathrm{~h}$ at $37 \mathrm{C}^{\circ}$ in humidified atmosphere. After 72 hours, MTT was added followed by DMSO and absorbance was recorded. $\mathrm{IC}_{50}$ (inhibitory concentration required to bring about death of $50 \%$ cells) and cell survival fraction values were calculated as mean $\pm \mathrm{SD}$ of at least five experiments. Cell survival fraction was calculated as:

Cell survival fraction $=$ absorbance sample/absorbance blank

The one-way analysis of variance (ANOVA) was used to decide whether there were any statistically significant differences between the control and treated cells at $* \mathrm{P}<0.05, * * \mathrm{P}<$ 0.005 and $* * * \mathrm{P}<0.0005$.

\section{Cytotoxicity Assay for Combination Effect-Median Effect Principle}

In this experiment, combined drug action was studied through the median effect principle to determine whether combinations resulted in antagonistic, synergistic or additive effect. The median effect analysis was done to

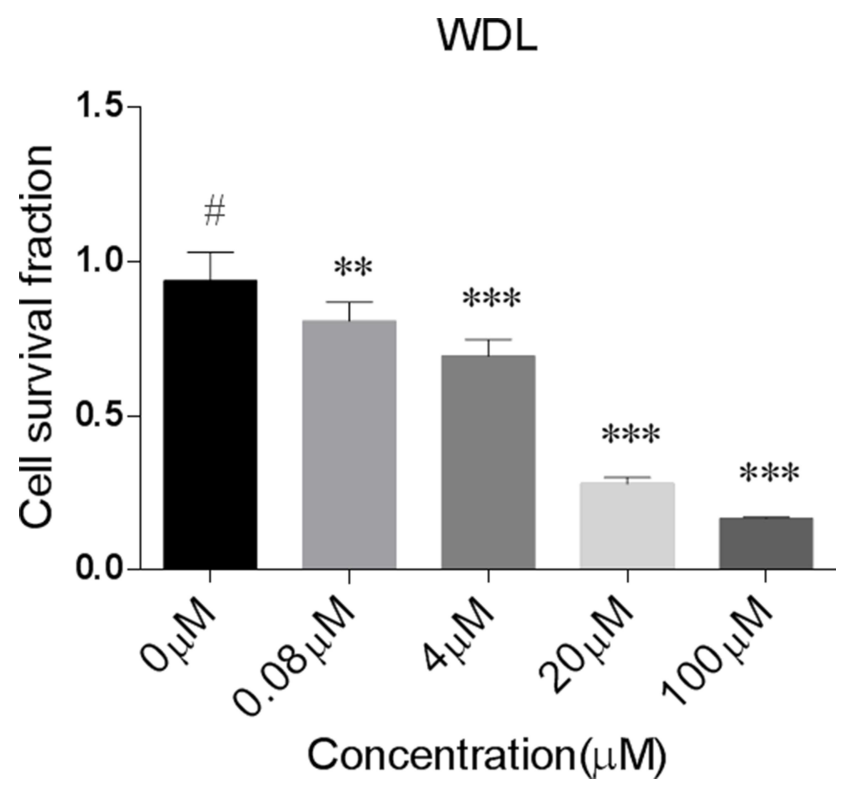

Figure I Cell survival fraction values as observed in HeLa in response to different doses of WDL. Significantly effective treatments compared to untreated control (shown as \#) are indicated as ** $(\mathrm{P}<0.005)$ and $* * *(\mathrm{P}<0.0005)$. determine combination index (CI) values following the methods of Chou and Talalay. The CI was calculated using the following equation:

$$
C I=\frac{D 1}{D 1 x}+D 2 / D 2 x
$$

Where $D 1$ and $D 2$ represent the concentrations of compound 1 and 2 in combination to achieve $\mathrm{x} \%$ inhibition whereas $D 1 \mathrm{x}$ and $D 2 \mathrm{x}$ represent concentrations of compounds 1 and 2 to achieve $\mathrm{x} \%$ inhibition when present alone. $D \mathrm{x}$ can be readily calculated from the following equation:

$$
D x=D m[f a /(1-f u) 1 / m
$$

Where $D m$ represents the median effect dose or $\mathrm{IC}_{50}, f a$ is the fraction of killed (affected) cells by the dose, $f_{u}$ is the fraction of cells remaining unaffected (living cells) so that $f u=1-f a$ and $\mathrm{m}$ is the exponent defining the shape of the dose effect curve. Based on these calculated CI values, dose reduction index (DRI) was calculated. DRI provides an estimation of the extent to which a dose of a single or more drugs or agents in combination can be decreased to get effect levels comparable with single drugs. The $\mathrm{CI}$ of $<1,=1$ and $>1$ indicates synergism, additiveness and antagonism in combined drug action respectively. Drug combinations that acted synergistically can be identified as those that exhibited significant dose reduction values. The $\mathrm{CI}, D_{m}$ and linear correlation coefficient $r$ values were calculated using Calcusyn software (V2) (Biosoft, UK). The $r$ values indicate goodness of fit for the pooled data (where $r=1$ is a perfect fit) and $r$ of median effect plot for the cell culture system should be greater than $0.95 .^{26-28}$ Investigation of synergism from combination of cisplatin with WDL and BA was the main focus of the study. Drugs were added either at the same time (simultaneous addition, $0 / 0 \mathrm{~h}$ ) or one followed by another after $4 \mathrm{~h}$ (sequential addition, 0/4 $\mathrm{h}$ and $4 / 0 \mathrm{~h}$ ). The results of combination studies, analysed using the program CalcuSyn that calculates a quantity called $\mathrm{CI}$ as a function of fraction affected $\mathrm{f}_{\mathrm{a}}$ and DRI (Supplementary Table).

\section{Molecular Docking Analysis \\ Retrieval of Target Proteins from PDB}

The three dimensional (3D) structures of protein targets; protein kinase B $(A k t)$, B-cell lymphoma-2 protein $(B c l-2)$, B-cell lymphoma-extra-large Protein $(B c l-x L)$ and nuclear factor kappa-light-chain-enhancer protein of activated B cells $(N F-k B)$ having PDB IDs: $1 \mathrm{GZK}, 4 \mathrm{LXD}, 4 \mathrm{TUH}$ and 2RAM respectively were accessed from Protein Data Bank (PDB). ${ }^{29}$ The selected target protein structure were 
minimized by using Autodock Tools. Gasteiger charges were added and were saved in pdbqt format. ${ }^{30}$

\section{Designing of Ligands}

The ligands WDL and BA were sketched and energy minimized in Discovery Studio Visualizer and saved in PDB format. Gasteiger charges were added using AutoDock tools in ligand structures to obtain the good structure conformation and were saved in pdbqt format.

\section{Detection of Binding Site}

Binding site for each protein target was detected using DOG Site Scorer. Best pocket depending on the druggabilty was selected as binding site. The three-dimensional coordinates of the binding site for each protein target were as; protein kinase $\mathrm{B}$ (Akt) PDB ID: $1 \mathrm{GZK}$; center $\mathrm{x}=$ -32.61 , center $\mathrm{y}=91.69$, center $\mathrm{z}=-64.88$ size $\mathrm{x}=28$, size $y=20$, size $z=34$. B-cell lymphoma 2 protein $(B c l-2)$ PDB ID: 4LXD; center $\mathrm{x}=22.02$, center $\mathrm{y}=29.36$, center $\mathrm{z}=6.19$ size $\mathrm{x}=28$, size $\mathrm{y}=22$, size $\mathrm{z}=22$. B-cell lymphoma-extra-large Protein $(B c l-x L)$ PDB ID: 4TUH; center $\mathrm{x}=-21.05$, center $\mathrm{y}=8.55$, center $\mathrm{z}=29.72$ size $\mathrm{x}=22$, size $\mathrm{y}=16$, size $\mathrm{z}=28$. Nuclear factor kappa-lightchain-enhancer protein of activated B cells $(N F-k B)$ PDB ID: $2 R A M$; center $\mathrm{x}=14.72$, center $\mathrm{y}=35.22$, center $\mathrm{z}=$ 17.778 size $x=28$, size $y=20$, size $z=22$.

\section{Docking}

Both the ligands were docked within the obtained binding pockets of the target proteins using AutoDock vina via PyRx. ${ }^{31,32}$ The exhaustiveness was set 50 and the best pose depending upon the lowest binding energy was obtained.

\section{Validation}

The overall docking protocol was validated by redocking the co-crystalized ligands after sketching them on Discovery Studio Visualizer. The obtained conformations as a result of docking were superimposed on the corresponding cocrystalized ligands extracted from the protein's 3D structure.

\section{Results}

\section{Cytotoxic Effects of Single Drugs}

The $\mathrm{IC}_{50}$ values of single drugs including WDL, BA and EGCG, as applied to the human cervical cancer cell line $\mathrm{HeLa}$, are given in Table 1. Among tested compounds BA was found to be most active while EGCG was least active. The $\mathrm{IC}_{50}$ values of WDL, BA and EGCG were $14.85 \pm 0.70$ $\mu \mathrm{M}, 12.82 \pm 0.37 \mu \mathrm{M}$ and $29.22 \pm 1.91 \mu \mathrm{M}$ respectively.
Table I IC $\mathrm{IC}_{50}$ Values of WDL, BA and EGCG as Observed in Cervical Cancer Cell Line HeLa

\begin{tabular}{|l|l|}
\hline Drugs & IC $_{\mathbf{5 0}}(\boldsymbol{\mu M})$ \\
\hline WDL & $14.85 \pm 0.70$ \\
BA & $12.82 \pm 0.37$ \\
EGCG & $29.22 \pm 1.91$ \\
\hline
\end{tabular}

Cell survival fraction values in response to WDL, BA and EGCG are given in the Figures 1-3. The effect was found out to be dose dependent where an inverse proportion (drug dose and surviving cells fraction) is clearly visible in most cases. The reduction in the number of surviving cells at $4 \mu \mathrm{M}, 20 \mu \mathrm{M}$ and $100 \mu \mathrm{M}$ of WDL (Figure 1); at $1.60 \mu \mathrm{M}$, $8 \mu \mathrm{M}, 40 \mu \mathrm{M}$ and $200 \mu \mathrm{M}$ of BA (Figure 2) while at $12 \mu \mathrm{M}$ and $60 \mu \mathrm{M}$ of EGCG (Figure 3) was highly significant than respective controls $(* * * \mathrm{P}<0.005)$.

\section{Cytotoxic Effects of Drugs in}

\section{Combination}

The study was conducted with the aim to investigate the outcome of the combination of selected phytochemicals with cisplatin in search of possible synergism in cervical cancer cell line HeLa using 0/0, 0/4 and 4/0 (as explained in methodology section) sequence of administration. This binary combination was investigated as function of sequence of drug administration and their concentration.

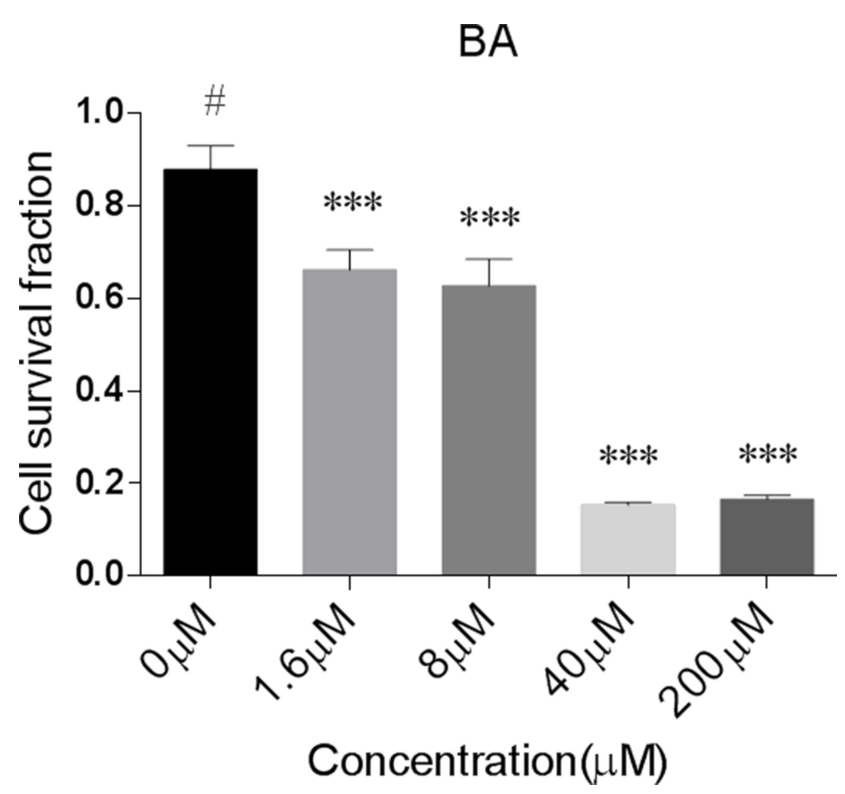

Figure 2 Cell survival fraction values as observed in HeLa in response to different doses of BA. Significantly effective treatments compared to untreated control (shown as \#) are indicated as $* * *(\mathrm{P}<0.0005)$. 


\section{EGCG}

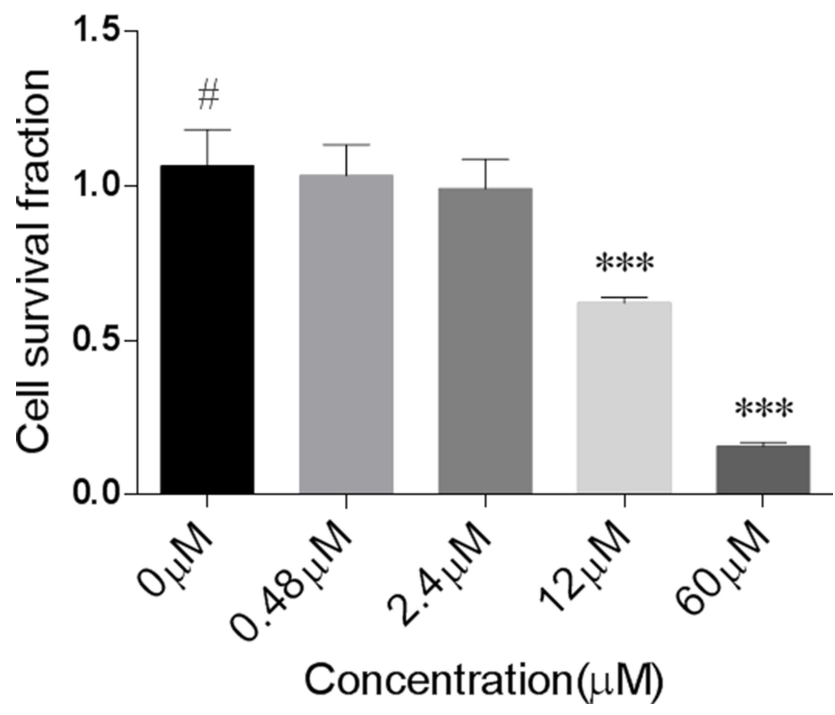

Figure 3 Cell survival fraction values as observed in HeLa in response to different doses of EGCG. Significantly effective treatments compared to untreated control (shown as \#) are indicated as $* * *(\mathrm{P}<0.0005)$.

Combined drug action was measured through doseresponse effect (qualitative method; Supplementary Table) and the combination indices (quantitative; Table 2) at median effect dose $E D_{50}$. In Table 2, dose effect parameters in terms of median dose effect $(\mathrm{Dm})$, sigmoidicity or shape $(\mathrm{m})$ and conformity or linear correlation coefficient (r) are given.

Combination indices show that administration of WDL in combination with the cisplatin resulted in nearly to synergistic effect at all the sequences of combined drug administration; this effect was more remarkable when either of the two drugs is used 4 hours before the other (Table 2 and Supplementary Table). The combination of BA with cisplatin, however, showed a synergistic trend when administered as bolus (both drugs applied at same time) while moderately antagonistic effect was observed on application of one drug (either) 4 hours before the other (Supplementary Table).

\section{Docking Analysis}

The docking results of both BA and WDL showed satisfactory binding affinities. WDL appeared to form stronger interactions with $A k t$ and $N F-k B$ (Figures $4 \mathrm{~A}-\mathrm{B}$ and $5 \mathrm{~A}-\mathrm{B}$ ) as compared to BA (Figures $6 \mathrm{~A}-\mathrm{B}$ and $7 \mathrm{~A}-\mathrm{B}$ ). It showed higher binding affinity with E-value of -7.6 $\mathrm{Kcal} / \mathrm{Mol}$ and $-7.7 \mathrm{Kcal} / \mathrm{Mol}$ with $A k t$ and $N F-k B$ respectively, whereas, BA had the binding energies of -5.5
Table 2 Combination Indices (Cls) at $\mathrm{ED}_{50}$ in Response to the Binary Combinations of Cisplatin with WDL and BA Using $(0 / 0$ h), $(0 / 4 \mathrm{~h})$ and $(4 / 0 \mathrm{~h})$ Sequence of Administration in Cervical (HeLa) Cancer Cell Line

\begin{tabular}{|c|l|l|l|l|}
\hline Drugs & $\begin{array}{l}\text { Combination Index }(\mathbf{C l}) \\
\text { Values at ED }\end{array}$ & $\mathbf{D}_{\mathbf{m}}$ & $\mathbf{M}$ & $\mathbf{r}$ \\
\hline Cisplatin & N/A & 5.21 & 0.77 & 0.99 \\
WDL & N/A & 58.35 & 0.59 & 0.69 \\
$0 / 0$ & 0.80 & 0.78 & 1.81 & 0.98 \\
$0 / 4$ & 0.66 & 0.64 & 1.42 & 0.98 \\
$4 / 0$ & $0.7 \mathrm{I}$ & 0.69 & 1.33 & $\mathrm{I}$ \\
\hline Cisplatin & N/A & 1.03 & 0.77 & 0.99 \\
BA & N/A & 9.3 & 0.64 & 0.87 \\
0/0 & 0.66 & 0.48 & 2.63 & 1 \\
0/4 & 1.3 & 0.95 & 1.81 & 0.93 \\
4/0 & 1.24 & 0.91 & 1.12 & 0.94 \\
\hline
\end{tabular}

Notes: $\mathrm{Dm}$ is the medium effect dose, $\mathrm{m}$ is the exponent defining shape of the dose effect curve and $r$ is the reliability coefficient.

$\mathrm{Kcal} / \mathrm{Mol}$ and $-6.4 \mathrm{Kcal} / \mathrm{Mol}$ respectively (Table 3). The difference in binding energy is clear from the binding interaction. WDL formed 4 hydrogen bonds with $\mathrm{Akt}$, whereas, BA 2 hydrogen bonds. Although WDL formed 1 unfavorable donor donor interaction with $A k t$, still the total number and strength of favorable interactions was way more than the single unfavorable interaction. In case of NF- $k B$, both WDL and BA formed 2 hydrogen bonds but the number of other favorable interactions formed by WDL with $N F-k B$ was sufficiently high which accounted for the higher binding affinity of WDL with the receptor.

On the other hand, BA appeared to bind more strongly (Figures 8A-B and 9A-B) as compared to WDL with Bcl2 and $\mathrm{Bcl}-\mathrm{xL}$ (Figures 10A-B and 11A-B). The pattern of binding interactions also confirms the difference in binding energies, as in case of Bcl-2, BA forms 1 hydrogen bond and 6 strong Alkyl-Alkyl and Pi-Alkyl interactions. Whereas, WDL formed no hydrogen bond and 5-AlkylAlkyl and Pi-Alkyl interactions.

When docked with $B c l-x L$, both WDL and BA formed 1 hydrogen bond but Alkyl-Alkyl and Pi-Alkyl interactions were higher in number and stronger for BA as compared to WDL. Furthermore, betulinic acid (BA), being a more nonpolar molecule, formed strong hydrophobic interactions with the receptor that resulted in its higher binding affinity as compared to WDL.

Overall, both molecules showed satisfactory binding energies and can be considered as good candidates for the selected targets. 


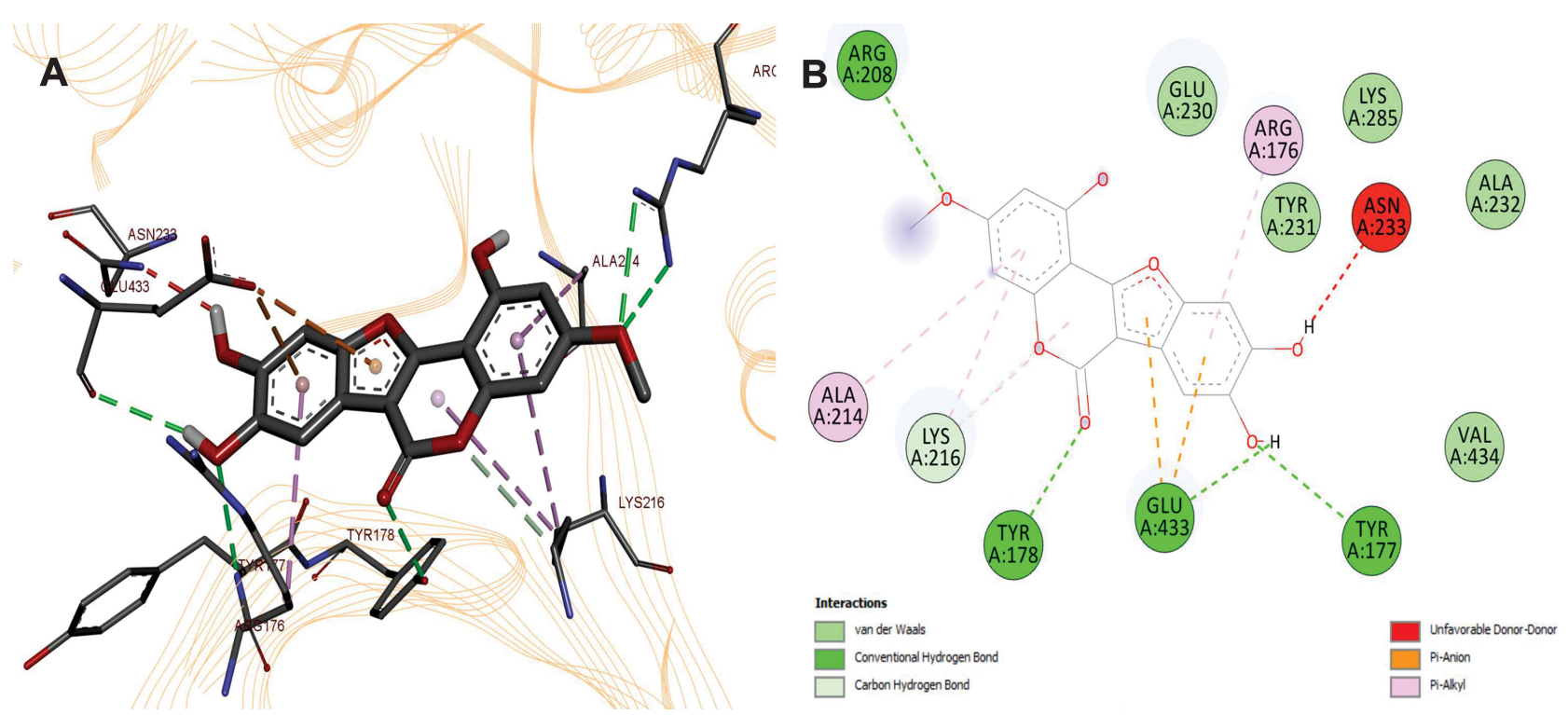

Figure 4 (A) 3D and (B) 2D poses of WDL with Protein kinase B (AkT) PDB ID: IGZK.
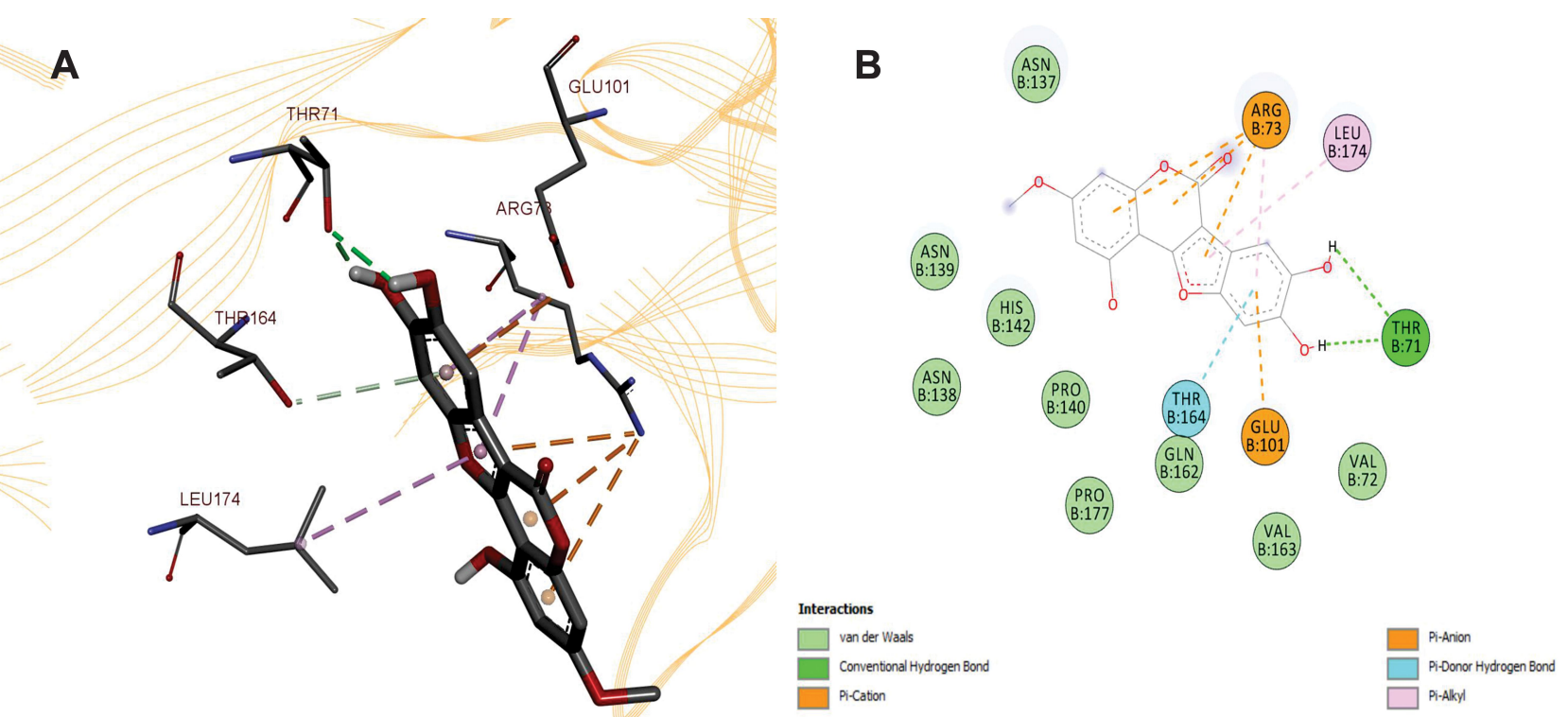

Figure 5 (A) 3D and (B) 2D poses of WDL with Nuclear factor kappa-light-chain-enhancer Protein of activated B cells (NF-kB) PDB ID: 2RAM.

\section{Discussion}

Cisplatin is being used extensively to treat cervical cancer. However, drug resistance and cytotoxicity are its two major limitations. Research is ongoing to overcome its toxicity and to ameliorate cisplatin sensitivity. The identification of chemosensitizers for cancer chemotherapy is an area of intensive investigation. Herbal remedies are emerging not only as chemosensitizers, but also as popular agents for cancer patients dealing with the side effects of chemotherapy. ${ }^{33}$ The aim of this investigation was the search for ideal combination/s of cisplatin with phytochemicals with the potential of working synergistically against cervical cancer cells. A synergistic effect is a combined effect which is numerically better than that obtained by either of single drugs. ${ }^{34}$ Due to their lower $\mathrm{IC}_{50}$ values, which were calculated in first part of this investigation, WDL and BA were selected for combination with cisplatin. The combination was taken as a function of concentration and sequence of drug addition. To the best of our knowledge the possible synergistic effect of WDL in combination with cisplatin is not investigated previously. Furthermore, in this investigation, it was established for the 1st time that WDL is cytotoxic against cervical cancer as determined in 

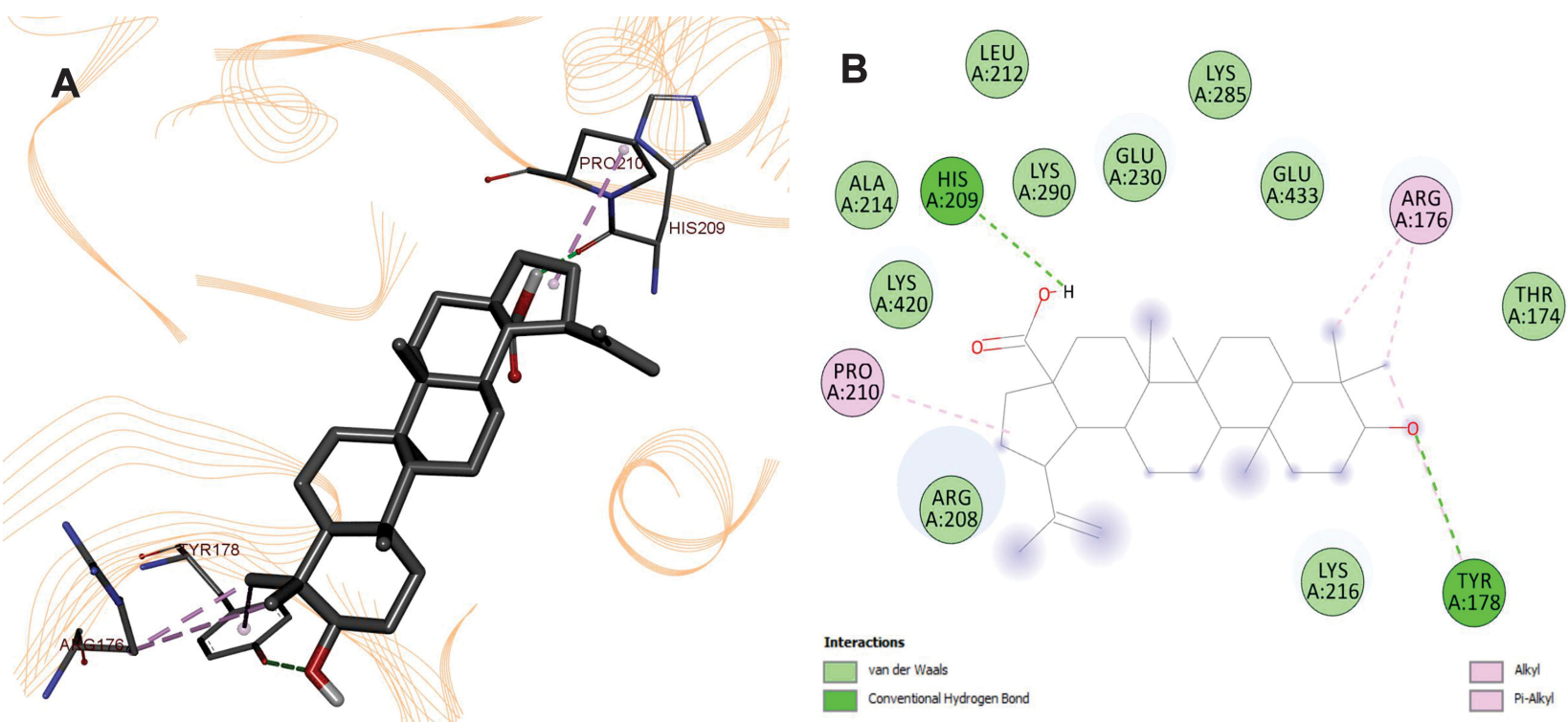

Figure 6 (A) 3D and (B) 2D poses of BA with Protein kinase B (AkT) PDB ID: IGZK.
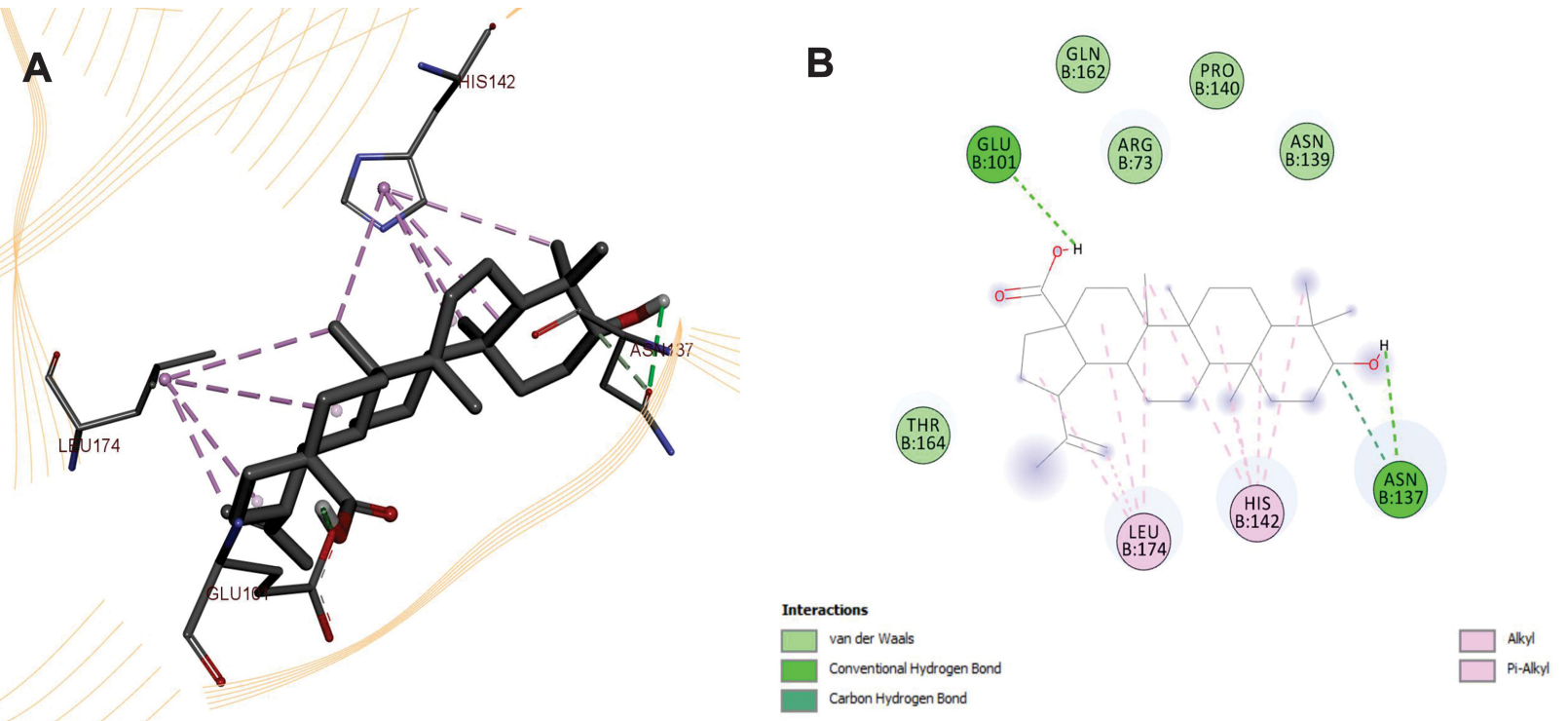

Figure 7 (A) 3D and (B) 2D poses of BA with Nuclear factor kappa-light-chain-enhancer Protein of activated B cells (NF-kB) PDB ID: 2RAM.

HeLa cell line. The binary combination of cisplatin with WDL in all three sequences of administration resulted in synergistic

Table 3 Binding Affinities $(\mathrm{Kcal} / \mathrm{Mol})$ of $\mathrm{WDL}$ and BA with Target Proteins

\begin{tabular}{|l|l|l|}
\hline \multirow{2}{*}{ Protein } & \multicolumn{2}{|l|}{ Binding Affinity (Kcal/Mol) } \\
\cline { 2 - 3 } & BA & WDL \\
\hline$A k t$ & -5.5 & -7.6 \\
$B C L-2$ & -7.8 & -7.4 \\
$B C L-X L$ & -8.0 & -7.4 \\
$N F-K B$ & -6.4 & -7.7 \\
\hline
\end{tabular}

( $0 / 4$ and $4 / 0$ administration) or nearly synergistic ( $0 / 0)$ outcome (Table 2; Supplementary Table for more explanation). Among the three administered combinations of cisplatin with BA, bolus (0/0) administration was found out to be synergistic while $0 / 4$ and $4 / 0$ sequence was antagonistic, highlighting that both compounds if administered simultaneously (co- treatment; 0/0) can result in better outcome through sensitization of HeLa cells towards cisplatin (Table 2).

Cisplatin mediated anticancer effect is interlinked to several other associated signaling pathways and so is the development of resistance. Inactivation of cisplatin- 

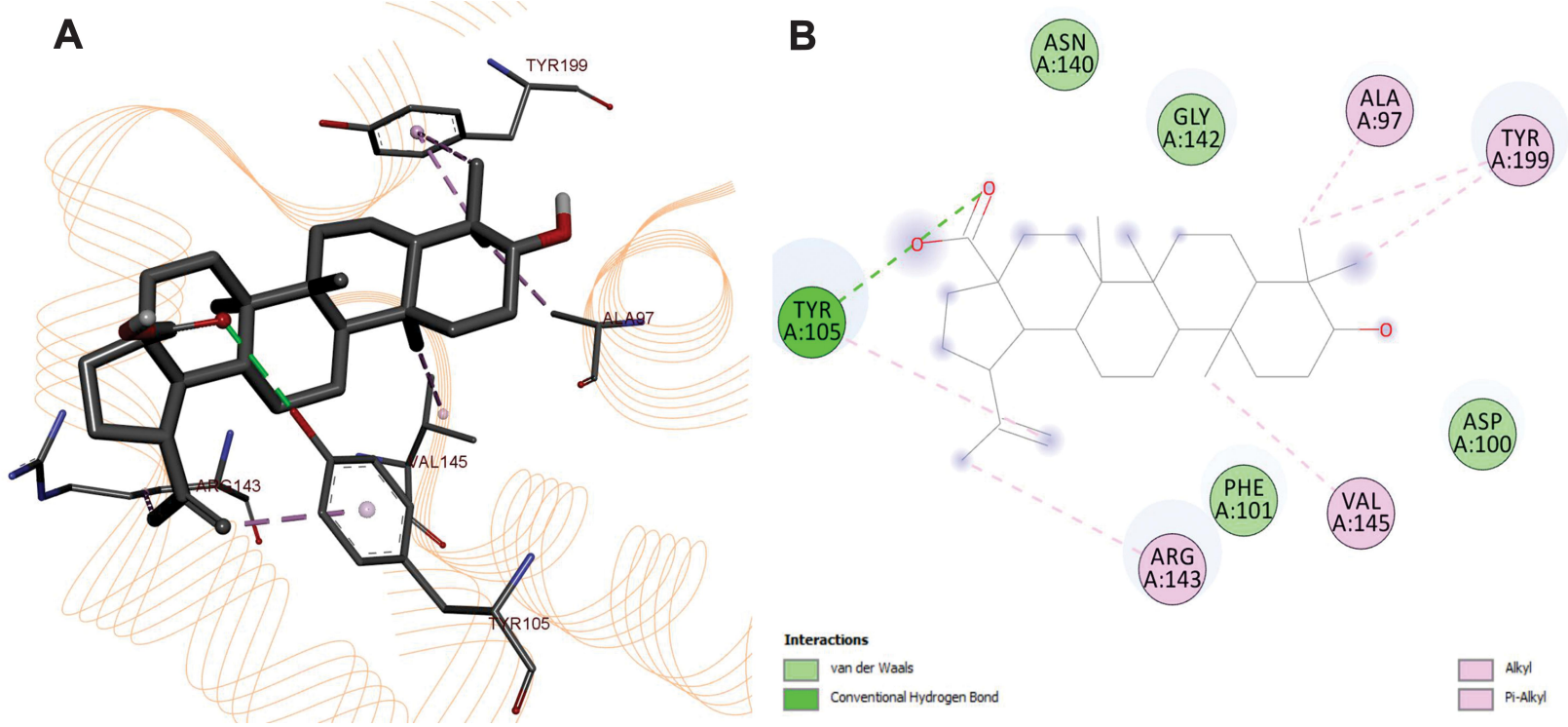

Figure 8 (A) 3D and (B) 2D poses of BA with B-cell lymphoma 2 Protein (Bcl-2) PDB ID: 4LXD.
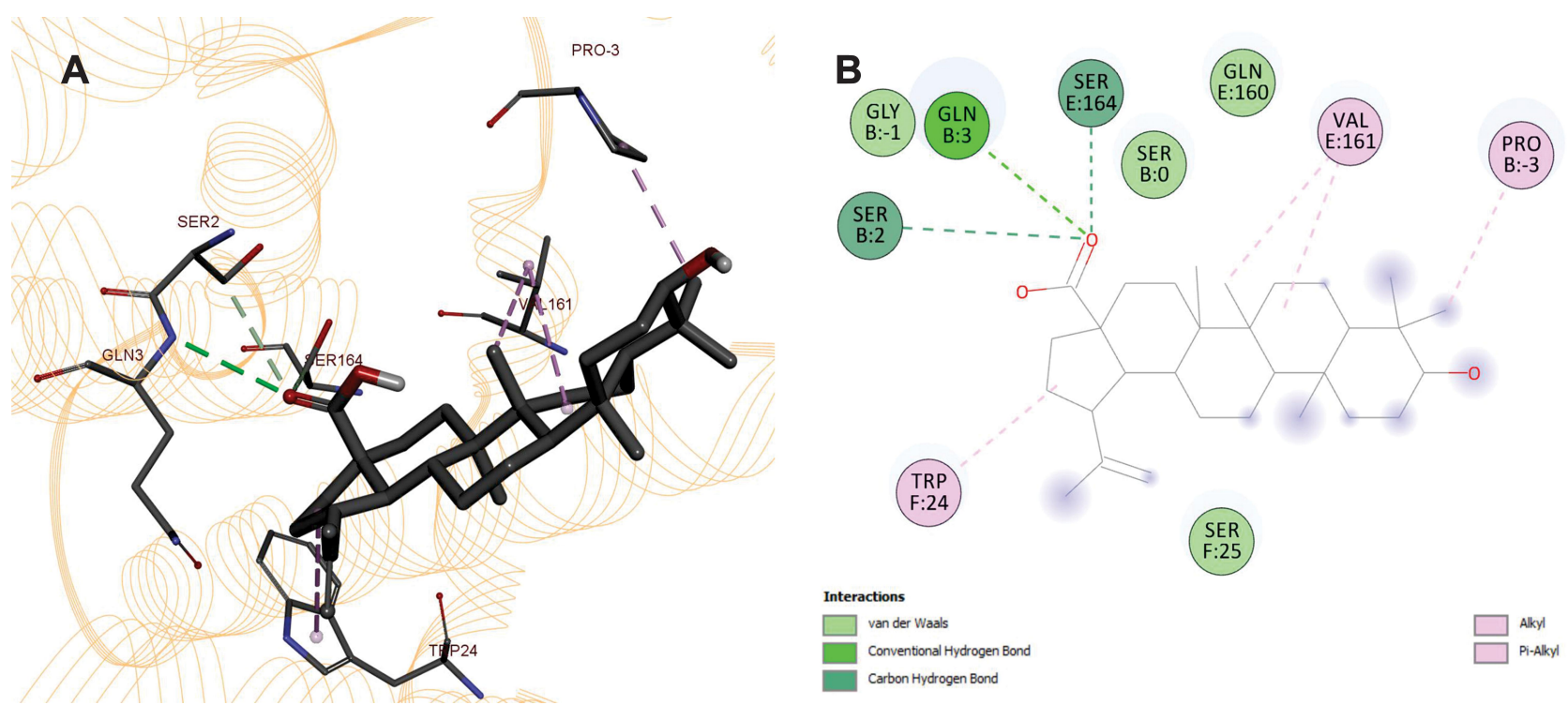

Figure 9 (A) 3D and (B) 2D poses of BA with B-cell lymphoma-extra large Protein (Bcl-xL) PDB ID: 4TUH.

induced apoptosis is a considerable factor in this regard which can contribute towards resistance. Cisplatininduced apoptosis works not only through DNA damage cascade but also through triggering of extrinsic death receptor or that of intrinsic mitochondrial pathway. Key elements involved here are nuclear factor-kB (NF-kB), $M A P K$ pathways, $B c l-2$ family and $B c l-x L$ family proteins (Figure 12A-C). Dysfunction of these proteins and pathways can lead to the development of resistance to cisplatin-induced apoptosis. ${ }^{35}$ Cisplatin resistant cervical cancer cells have been found to overexpress the antiapoptotic $\mathrm{Bcl}-2$ family proteins (Figure 12C). ${ }^{36} \mathrm{BA}$ is reported to suppress the expression of $B c l-2$ transcripts (anti-apoptosis proteins of $\mathrm{Bcl}-2$ family) in HeLa cells. ${ }^{12}$ Binding interactions of $\mathrm{BA}$ revealed more strong binding (Figures $8 \mathrm{~A}-\mathrm{B}$ and $9 \mathrm{~A}-\mathrm{B}$ ) as compared to $\mathrm{WDL}$ with $\mathrm{Bcl}-2$ and $\mathrm{Bcl}-x \mathrm{~L}$ (Figures $10 \mathrm{~A}-\mathrm{B}$ and $11 \mathrm{~A}-\mathrm{B})$. In our study, the synergism observed at bolus $(0 / 0)$ administration of BA with cisplatin might have resulted from the activation of the intrinsic mitochondrial apoptosis pathway, involving inhibition of over activated $N F-k B$ and $B c l-2$ entities (as explained in Figure 12A and C), resulting in the enhancement of BA-induced apoptosis of cervical cancer cells (HeLa). 

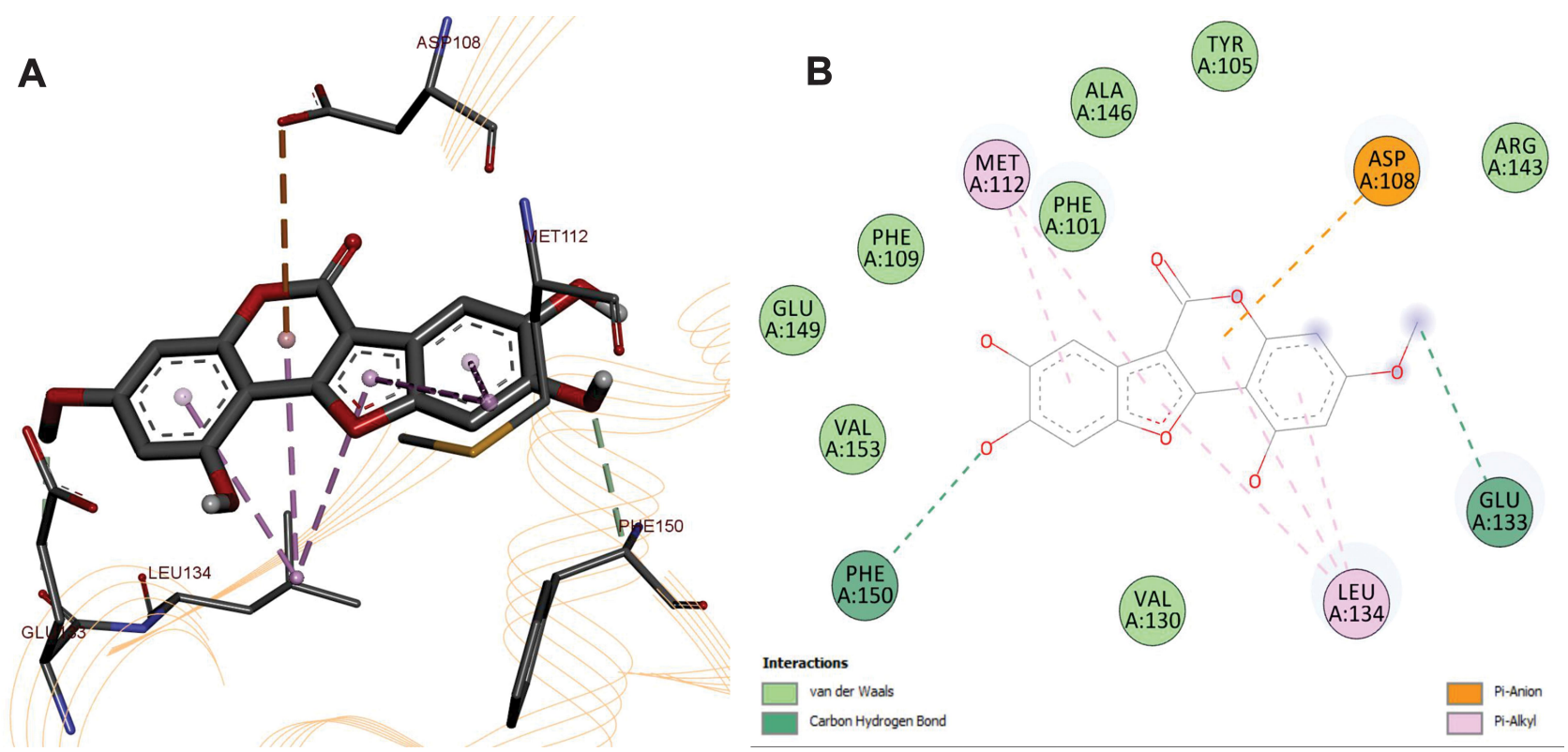

Figure 10 (A) 3D and (B) 2D poses of WDL with B-cell lymphoma 2 Protein (Bcl-2) PDB ID: 4LXD.
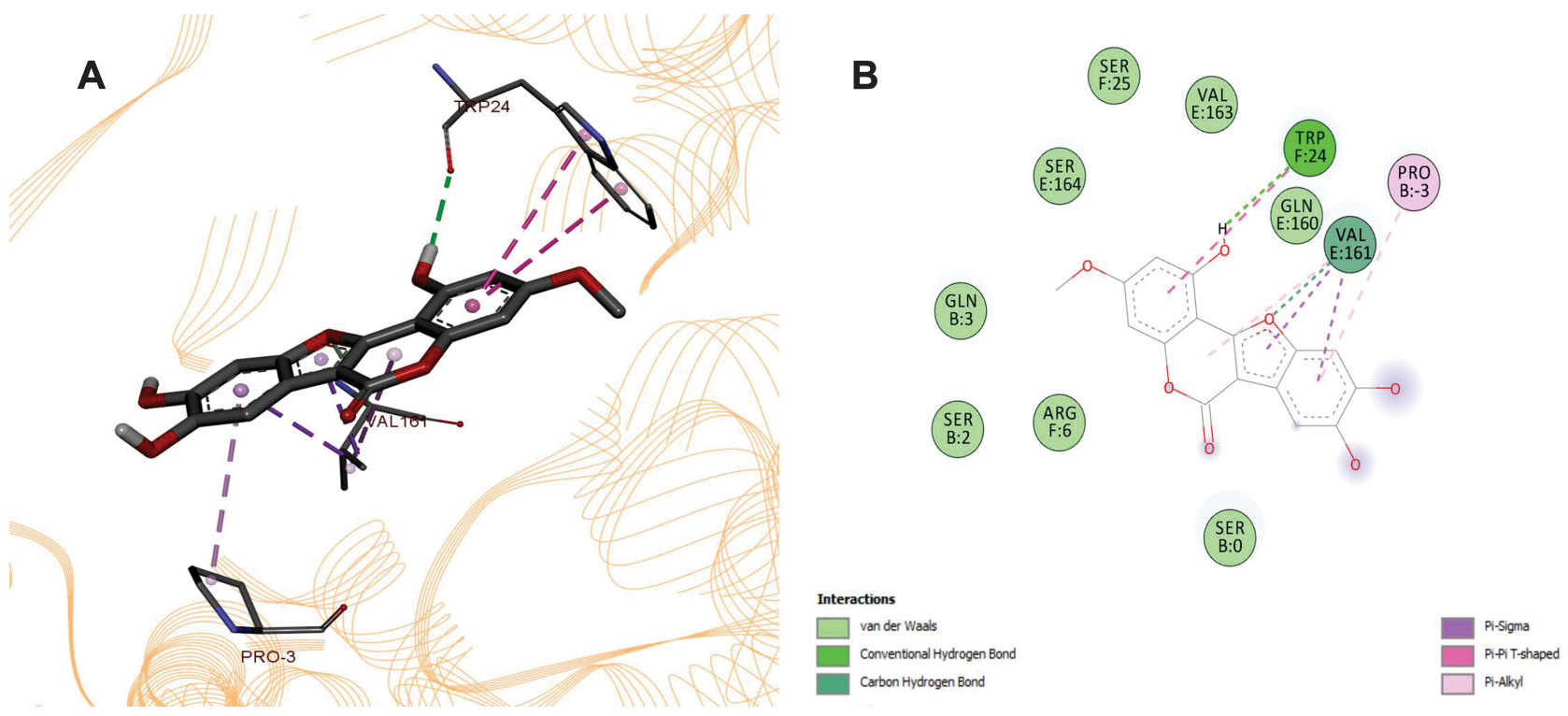

Figure I I (A) 3D and (B) 2D poses of WDL with B-cell lymphoma-extra large Protein (Bcl-xL) PDB ID: 4TUH.

The association of $M A P K$ and cisplatin resistance has been recognized (Figure 12A). Cisplatin-induced activation of $S A P K / J N K$ and ERK (three main types of MAPKs) in cisplatin-sensitive HeLa cells while inhibition of this activation of $S A P K / J N K$ is reported in resistant cells. WDL has been reported to induce apoptosis through activation of $J N K$ in prostate cancer cells. ${ }^{37}$ WDL has also been previously reported to inhibit the activated $N F-k B$ in multiple cancer types in in vitro studies. ${ }^{38,39}$ Another key factor involved in resistance is $A k t$. The activation of the Akt pathway has a role in the development of chemotherapeutic drug resistance and reduction of the apoptotic potential of chemotherapeutic agents in several cancer types. The inhibitors of the the Akt pathway can improve cisplatin-induced chemotherapy. ${ }^{40} \mathrm{WDL}$ is also reported as a potent inhibitor of the Akt signaling pathway ${ }^{41}$. This effect has been validated through our docking experiment through 


\section{A}

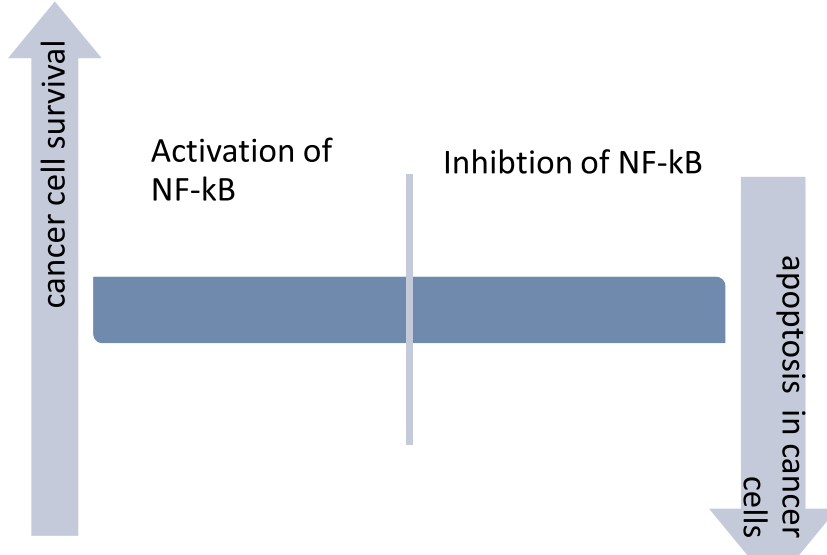

B

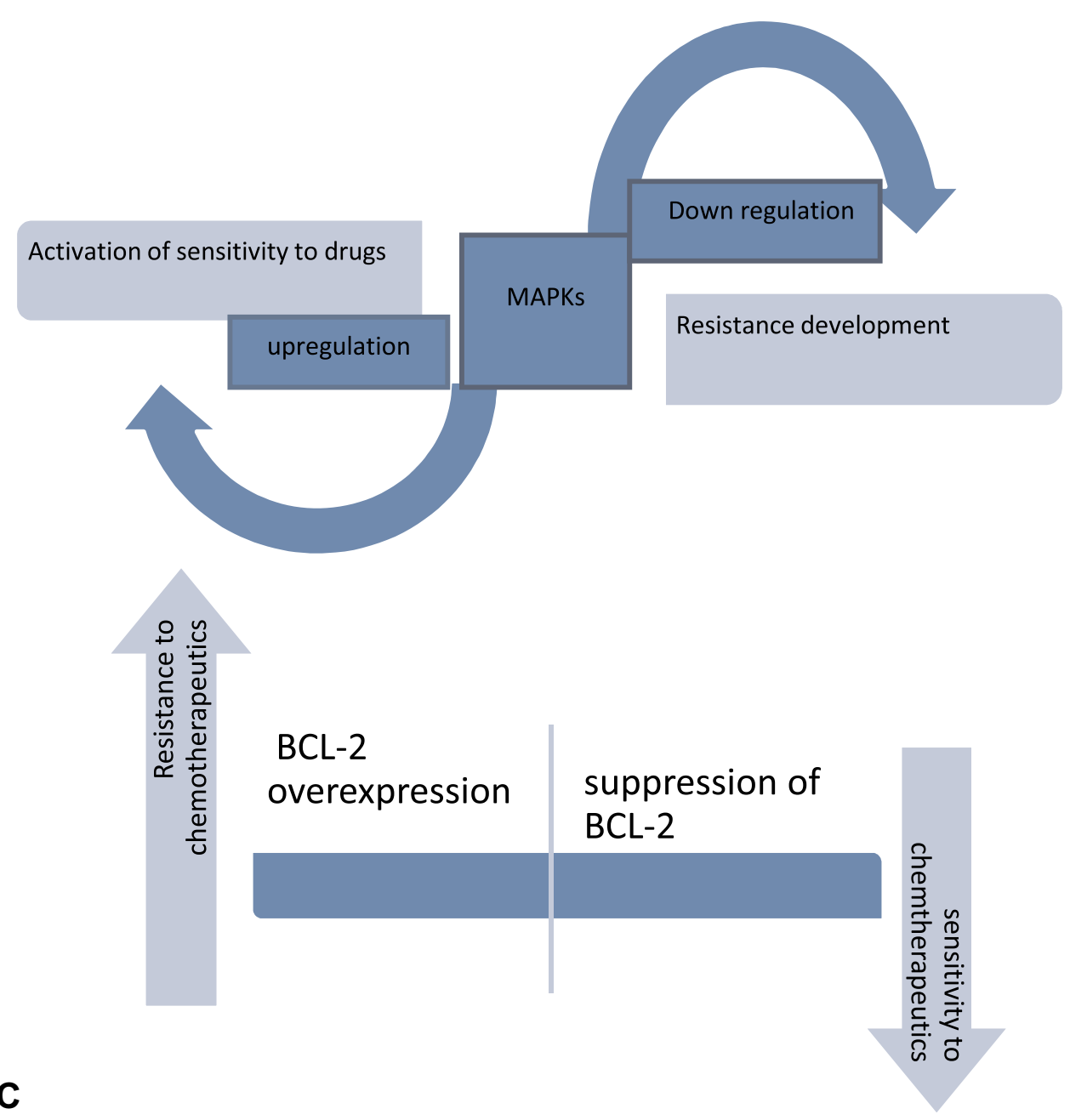

Figure 12 Proposed mechanisms of resistance in cervical cancer: (A) Activation of NF-kB (B) Down-regulation of MAPKs (C) Over expression of anti-apoptotic members of BCL-2 family.

AutoDock vina via PyRx. WDL formed stronger interactions with both $A k t$ and $N F-k B$ (Figures 4 and 5) as compared to BA. Thus, the increased inhibition of growth of cervical cancer cells resulting from the addition of WDL may be through the regulation of the $A k t, N F-k B$, or $J N K$ pathway. 
One of the serious concerns in the cancer chemotherapy is further increase in the concentration of chemotherapeutic agent, thereby, increasing the cellular toxicity. Therefore, the sensitization of cisplatin-induced growth inhibition of HeLa cells by WDL and BA (at 0/0) may be a remedy for chemotherapeutic drug toxicity-induced damages. This combination is a less toxic option in the treatment of cervical cancer, especially in case of chemoresistance to cisplatin. Future studies are warranted to further investigate the effect of combination of WDL and cisplatin on key elements and pathways involved in cervical cancer resistance considering the urgent need to search for compensation of associated side-effects of current treatment options.

\section{Conclusion}

In conclusion, the combination of WDL and cisplatin has the potential to work synergistically towards the inhibition of growth of cervical cancer cells in any sequence of application. To the best of our knowledge, there is no any previous report of such action of WDL either individually or in combination.

\section{Acknowledgments}

The authors acknowledge the Higher Education Commission Pakistan for funding this project under Post-Doctoral Fellowship (Ref:2-6(14)/PDFP/HEC/2013/08). This work was done as part of postdoctoral fellowship by corresponding author and was performed at Discipline of Biomedical Science, School of Medicine, The University of Sydney, Australia. The corresponding author is currently working as Assistant Professor at Department of Pharmacognosy, Riphah Institute of Pharmaceutical Sciences, Riphah International University, Islamabad, Pakistan.

\section{Author Contributions}

All authors made a significant contribution to the work reported, whether that is in the conception, study design, execution, acquisition of data, analysis and interpretation, or in all these areas; took part in drafting, revising or critically reviewing the article; gave final approval of the version to be published; have agreed on the journal to which the article has been submitted; and agree to be accountable for all aspects of the work.

\section{Disclosure}

The authors report that they have no conflicts of interest for this work.

\section{References}

1. NIH National Cancer Institute. Surveillance, epidemiology and end results program; 2020. Available from: https://seer.cancer.gov/stat facts/html/cervix.html. Accessed June 19, 2020.

2. NCCN Clinical Practice Guidelines in Oncology ${ }^{\mathrm{TM}}$. Cervical Cancer. v1; 2012. Available from: http://www.ncen.org/professionals/physi cian_gls/pdf/cervical.pdf. Accessed August 21, 2020.

3. Keys HM, Bundy BN, Stehman FB, et al. Cisplatin, radiation, and adjuvant hysterectomy compared with radiation and adjuvant hysterectomy for bulky stage IB cervical carcinoma. $N$ Engl $J$ Med. 1999;340(1):1154-1161. doi:10.1056/NEJM199904153401503.

4. Rose PG, Bundy BN, Watkins EB, et al. Concurrent cisplatin based radiotherapy and chemotherapy for locally advanced cervical cancer. $N$ Engl $J$ Med. 1999;340(15):1144-1153. doi:10.1056/ NEJM199904153401502

5. Whitney CW, Sause W, Bundy BN, et al. Randomized comparison of fluorouracil plus cisplatin versus hydroxyurea as an adjunct to radiotherapy in stage IIB-IVA carcinoma of the cervix with negative para-aortic lymph nodes: a Gynaecologic Oncology Group and Southwest Oncology Group study. J Clin Oncol. 1999;17 (5):1339-1348. doi:10.1200/JCO.1999.17.5.1339

6. Morris M, Eifel PF, Lu J, et al. Pelvic radiation with concurrent chemotherapy compared with pelvic and para-aortic radiation for high-risk cervical cancer. $N$ Engl J Med. 1999;340(15):1137-1143. doi:10.1056/NEJM199904153401501

7. Dueñas GA, Zarbá JJ, Patel F, et al. Phase III, open label randomized study comparing concurrent gemcitabine plus cisplatin and radiation followed by adjuvant gemcitabine and cisplatin versus concurrent cisplatin and radiation in patients with stage IIB to IVA carcinoma of the cervix. J Clin Oncol. 2011;29(13):1678-1685. doi:10.1200/ JCO.2009.25.9663

8. Monk BJ, Sill MW, McMeekin DS, et al. Phase III trial of four cisplatin-containing doublet combinations in stage IVB, recurrent, or persistent cervical carcinoma: a Gynecologic Oncology Group study. J Clin Oncol. 2009;27(28):4649-4655. doi:10.1200/JCO.2009.21.8909

9. Moore DH, Blessing JA, McQuellon RP, et al. Phase III study of cisplatin with or without paclitaxel in stage IVB, recurrent, or persistent squamous cell carcinoma of the cervix: a gynecologic oncology group study. J Clin Oncol. 2004;22(15):3113-3119. doi:10.1200/ JCO.2004.04.170

10. Arany I, Safirstein RL. Cisplatin nephrotoxicity. Semin Nephrol. 2003;23:460-464. doi:10.1016/S0270-9295(03)00089-5.

11. Lewandowska U, Gorlach S, Owczarek K, Hrabec E, Szewczyk K. Synergistic interactions between anticancer chemotherapeutics and phenolic compounds and anticancer synergy between polyphenols. Postepy Hig Med Dosw. 2014;68(1):528-540. doi:10.5604/ 17322693.1102278

12. Xu T, Pang Q, Zhou D, et al. Proteomic Investigation into betulinic acid-induced apoptosis of human cervical cancer HeLa cells. PLoS One. 2014;9(8):e105768. doi:10.1371/journal.pone.0105768

13. Kilic U, Sahin K, Tuzcu M, et al. Enhancement of cisplatin sensitivity in human cervical cancer: epigallocatechin-3-gallate. Front Nutr. 2014;1:28. doi:10.3389/fnut.2014.00028.

14. Karin M. Nuclear factor -kappa B in cancer development and progression. Nature. 2006;4419(7092):431-436. doi:10.1038/ nature 04870

15. Zheng X, Lv J, Shen Q, et al. Synergistic effect of pyrrolidine dithiocarbamate and cisplatin in human cervical carcinoma. Reprod Sci. 2014;21(10):1319-1325. doi:10.1177/1933719114525272

16. Zhu H, Luo H, Zhang W, Shen Z, Hu X, Zhu X. Molecular mechanisms of cisplatin resistance in cervical cancer. Drug Design Devel Ther. 2016;10(2):1885-1895. doi:10.2147/DDDT.S106412

17. Siddik ZH. Cisplatin: mode of cytotoxic action and molecular basis of resistance. Oncogene. 2003;22(47):7265-7279. doi:10.1038/sj. onc. 1206933 
18. Dean M, Fojo T, Bates S. Tumor stem cells and drug resistance. Nat Rev Cancer. 2005;5(4):275-284. doi:10.1038/nrc1590

19. Wang X, Martindale JL, Holbrook NJ. Requirement for ERK activation in cisplatin induced apoptosis. $J$ Biol Chem. 2000;275 (50):39435-39443. doi:10.1074/jbc.M004583200

20. Basu A, Tu H. Activation of ERK during DNA damage-induced apoptosis involves protein kinase $\mathrm{C}$ delta. Biochem Biophys Res Commun. 2005;334(4):1068-1073. doi:10.1016/j.bbrc.2005.06.199

21. Negri A, Naponelli V, Rizzi F, Bettuzzi S. Molecular targets of epigallocatechin-gallate (EGCG): a special focus on signal transduction and cancer. Nutrients. 2018;10(12):1936. doi:10.3390/nu10121936

22. Millimouno FM, Dong J, Yang L, Li J, Li X. Targeting apoptosis pathways in cancer and perspectives with natural compounds from mother nature. Cancer Prev Res (Phila). 2014;7(11):1081-1107. doi:10.1158/1940-6207.CAPR-14-0136.

23. Zhang $\mathrm{X}, \mathrm{Hu}$ J, Chen Y. Betulinic acid and the pharmacological effects of tumor suppression (Review). Mol Med Rep. 2016;14 (5):4489-4495. doi:10.3892/mmr.2016.5792

24. Dhara S. A rapid method for the synthesis of cis-[Pt (NH3)2Cl2]. Indian J Chem. 1970;8(1):193-194.

25. Mosmann T. Rapid colorimetric assay for cellular growth and survival: application to proliferation and cytotoxicity assays. J Immunol Method. 1983;65(1-2):55-63. doi:10.1016/0022-1759(83)90303-4

26. Chou TC. Relations between inhibition constants and fractional inhibition on enzyme-catalyzed reactions with different numbers of reactants, different reaction mechanisms, and different types and mechanisms of inhibition. Mol Pharmacol. 1974;10(2):235-247.

27. Chou TC. Derivation and properties of Michaelis-Menten type and Hill type equations for reference ligands. J Theor Biol. 1976;59 (2):253-276. doi:10.1016/0022-5193(76)90169-7

28. Kalra J, Warburton C, Fang K, et al. QLT0267, a small molecule inhibitor targeting integrin-linked kinase (ILK), and docetaxel can combine to produce synergistic interactions linked to enhanced cytotoxicity, reductions in P-AKT levels, altered F-actin architecture and improved treatment outcomes in an orthotopic breast cancer model. Breast Cancer Res. 2009;11(3):R25. doi:10.1186/bcr2252

29. Berman HM, Westbrook J, Feng Z, et al. The protein data bank. Nucleic Acids Res. 2002;28(1):235-242. doi:10.1093/nar/28.1.235.

30. Morris GM, Huey R, Lindstrom W, et al. AutoDock4 and AutoDockTools4: automated docking with selective receptor flexibility. J Comput Chem. 2009;30(16):2785-2791. doi:10.1002/ jcc. 21256
31. Trott O, Olson AJ. AutoDockVina: improving the speed and accuracy of docking with a new scoring function, efficient optimization, and multithreading. J Comput Chem. 2010;31(2):455-461. doi:10.1002/ jec. 21334

32. Dallakyan S, Olson AJ. Small-molecule library screening by docking with PyRx. In: Hempel JE, Williams CH, Hong CC, Eds. Chemical Biology. New York, NY: Humana Press; 2015:243-250.

33. Luo T, Wang J, Yin Y, et al. (-)-Epigallocatechin gallate sensitizes breast cancer cells to paclitaxel in a murine model of breast carcinoma. Breast Cancer Res. 2010;12(1):R8. doi:10.1186/bcr2473

34. Tallarida RJ. Combination analysis. Adv Exp Med Biol. 2010;678 (1):133-137.

35. Zhu H, Luo H, Zhang W, Shen Z, Hu X, Zhu X. Molecular mechanisms of cisplatin resistance in cervical cancer. Drug Design Devel Ther. 2016;10(1):1885-1895. doi:10.2147/DDDT.S106412

36. Chen J, Xiong J, Liu H, Chernenko G, Tang S. Distinct BAG-1 isoforms have different anti-apoptotic functions in BAG-1 transfected C33A human cervical carcinoma cell line. Oncogene. 2002;21 (46):7050-7059. doi:10.1038/sj.onc. 1205845

37. Sarveswaran S, Gautam SC, Ghosh J. Wedelolactone, a medicinal plant-derived coumestan, induces caspase-dependent apoptosis in prostate cancer cells via down regulation of PKCE without inhibiting Akt. Int J Oncol. 2012;41(6):2191-2199. doi:10.3892/ijo.2012.1664

38. Vender JR, Laird MD, Dhandapani KM. Inhibition of NF $\mathrm{B}$ reduces cellular viability in GH3 pituitary adenoma cells. J Neurosurg. 2008;62(5):1122-1128. doi:10.1227/01.neu.0000325874.82999.75

39. Chaudhary H, Dhuna V, Singh J, Kamboj SS, Seshadri S. Evaluation of hydro-alcoholic extract of Eclipta alba for its anticancer potential: an in vitro study. $J$ Ethnopharmacol. 2011;136(2):363-367. doi:10.1016/j.jep.2011.04.066

40. Singh M, Bhui K, Singh R, Shukla Y. Tea polyphenols enhance cisplatin chemosensitivity in cervical cancer cells via induction of apoptosis. Life Sci. 2013;93(1):7-16. doi:10.1016/j.1fs.2013.02.001

41. Hsieh CJ, Kuo P, Hou M, et al. Wedelolactone inhibits breast cancer-induced osteoclastogenesis by decreasing Akt $/ \mathrm{mTOR}$ signaling. Int $J$ Oncol. 2014;46(2):555-562. doi:10.3892/ ijo. 2014.2769

\section{Publish your work in this journal}

Drug Design, Development and Therapy is an international, peerreviewed open-access journal that spans the spectrum of drug design and development through to clinical applications. Clinical outcomes, patient safety, and programs for the development and effective, safe, and sustained use of medicines are a feature of the journal, which has also been accepted for indexing on PubMed Central. The manuscript management system is completely online and includes a very quick and fair peer-review system, which is all easy to use. Visit http://www. dovepress.com/testimonials.php to read real quotes from published authors. 